\title{
Las lágrimas y sus padecimientos
}

\author{
Anabel Socorro Sánchez Sánchez y Alejandro Rodriguez Mercado
}

\section{Resumen}

Las lágrimas son un componente esencial para nuestra visión, son el primer punto de contacto con la luz que entra a los ojos. Sin embargo, resulta común vivir con uno o varios síntomas asociados con padecimientos lagrimales y estar tan acostumbrados a ellos que los pasamos por alto. Cualquier problema de este tipo afectará nuestra visión y la manera en la que percibimos el mundo. En este artículo, te hablaremos sobre qué son las lágrimas, también llamadas películas lagrimales, de qué están hechas y cómo podrías identificar si vives con algún problema en ellas.

Palabras clave: lágrima, visión, ojos, padecimientos.

\section{TEARS AND ITS AFFECTIONS}

\begin{abstract}
Tears are an essential component for our vision; they are the first contact of the light when it passes through our eyes. It is common to live with one or more symptoms associated to issues in the tears, overlooking that fact. Any tear-related problem compromises our vision and our world perception. In this article, we will talk about what tears are, which are their components and how you can assess yourself to identify if you are living with some problem in them.
\end{abstract}

Keywords: tears, vision, eyes, health condition. 
Egresada de la Licenciatura en Optometría. Cursó estudios de maestría en la Escuela Superior de Ingeniería Mecánica y Eléctrica y se graduó con la tesis: Análisis sistémico comparativo de procedimientos LASER en córnea. Cursó el doctorado en el Centro de Investigación y de Estudios Avanzados unidad Zacatenco y realizó la tesis: Metodología clínica instrumental ex profeso para el estudio de la dinámica pupilar pre y post cirugía ocular. Actualmente, es investigadora dentro del Posgrado en Ciencias y Tecnologías Biomédicas en el Instituto Nacional de Astrofísica Óptica y Electrónica y profesora de tiempo parcial en el Centro Interdisciplinario de Ciencias de la Salud Unidad de Santo Tomás del Instituto Politécnico Nacional.

\section{Alejandro Rodriguez Mercado}

alx_romerc@hotmail.com

orcid.org/0000-0003-0839-9012

Egresado de la Licenciatura en Optometría, becario del Programa Institucional para Formación de Investigadores, durante 2 años y medio, graduándose con la tesis: Relación de la Función de Sensibilidad al Contraste con las Oscilaciones de Glucosa en Pacientes Diabéticos. Trabajó como responsable vespertino del departamento de Lentes de Contacto del hospital Fundación de Asistencia Privada "Conde de Valenciana" IAP. Certificación Avanzada en Lentes de Contacto por el Australian College of Optometry. Actualmente se dedica a la práctica privada.

\section{Introducción}

¿Te ha pasado que sientes que nadie merece tus lágrimas? O tal vez has imaginado como sería tu vida sin lágrimas, quizá porque el viento se las llevó o porque fueron derramadas en la sequedad o aspereza.

Quizá simplemente las has secado, sin considerar lo importantes que son para tus ojos, pasando por alto también la labor de las glándulas que intervienen en su formación. Las diferentes cualidades ópticas de las lágrimas hacen posible ver una imagen definida, además de cumplir funciones de lubricación y otras más de defensa ante agentes microbianos. A continuación, se dan a conocer más detalles.

\section{Las lágrimas, lágrima o película lagrimal: una capa de capas}

La lágrima o película lagrimal es una capa líquida muy delgada; tiene un espesor

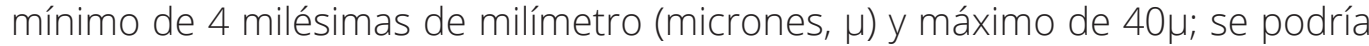
pensar en ella como un gel líquido compuesto de agua, grasa, moco y muchos nutrientes. Esta fina capa a su vez está formada por tres subcapas más delgadas, 
Figura 1. Capas de la lágrima. Fuente: elaboración propia.
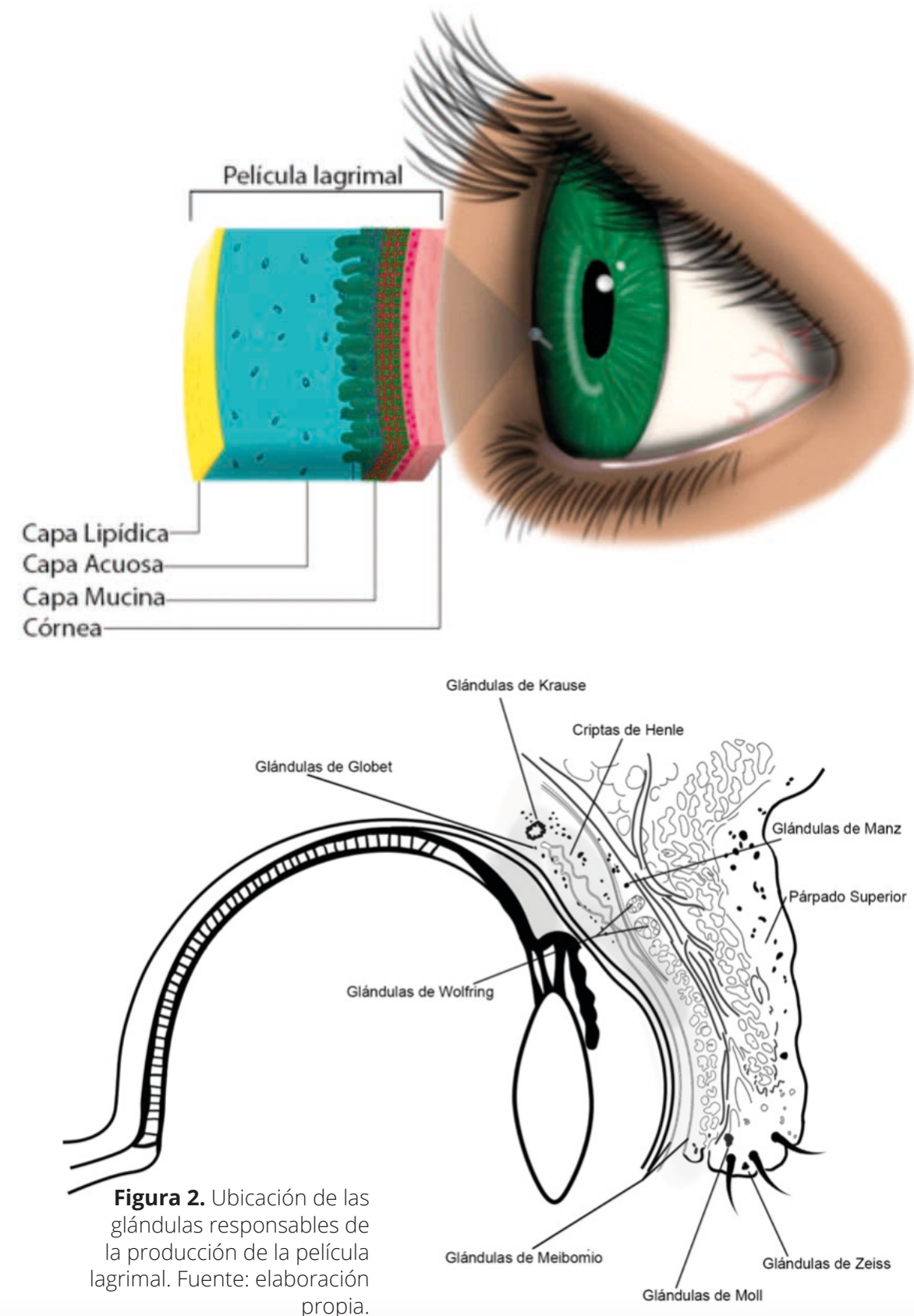

una de mucina, otra de agua y la última de lípidos o grasas, cada una con origen en glándulas diferentes, distribuidas en el aparato lagrimal. La acción mecánica del párpado combina estos 3 componentes, y forma, como tal, la película lagrimal (ver figura 1). Una definición más reciente, describe a la lágrima como un gel interactivo de mucina hidratada, con lípidos asociados a proteínas, distribuidos por todo el gel (Gayton, 2009).

Las lágrimas tienen muchas funciones: sirven como lente óptica, ya que son el primer punto de contacto que tiene la luz al entrar a nuestros ojos, son la principal fuente de oxígeno de la córnea, actúan como lubricante entre los párpados y la córnea, se encargan de la eliminación de cuerpos extraños y células muertas, además de prevenir infecciones por microorganismos.

La subcapa de mucina es la más próxima a la superficie ocular, y se genera en las células de Globet y epiteliales, en las glándulas de Manz y de Moll, y en las criptas de Henle (ver figura 2). Está constituida principalmente de sulfomucina y sialomucina (Caffery, 1990), proteínas de alto peso molecular; encargadas de proteger la superficie ocular al actuar como barrera ante microorganismos. Ayuda a crear una superficie hidrófila lisa sobre las microvellosidades de la superficie corneal y con esto favorecer la adherencia de la lágrima sobre el ojo (ver figura 3).

La subcapa acuosa se halla en la parte intermedia de la lágrima, y constituye la mayor parte de la película. Aunque su producción más grande procede de la glándula lagrimal principal, se complementa con la de las glándulas de Krause y Wolfring 1 (ver figura 2), células acinares, ${ }^{2}$ vasos sanguíneos de la conjuntiva, epitelio corneal y conjuntival. Está integrada por un alto contenido de agua, proteínas y enzimas (amilasa, lizosima, lactoferrina, prealbúmina), glicoproteínas, inmunoglobulinas (IgA e IgG), sodio, cloro, urea, piruvato, glucosa, potasio, calcio, magnesio e, incluso algunos otros componentes que aún no se
1 Glándulas complementarias en la producción acuosa de la lágrima.

2 Regulan la secreción de la capa acuosa. 
Figura 3. Adherencia de la mucina. Fuente: elaboración propia. han descubierto. Se encarga principalmente en llevar oxígeno y nutrientes a la córnea; además de lubricar, eliminar tanto partículas como desechos metabólicos, y gracias a la presencia de inmunoglobulinas, enzimas y otras proteínas bacteriolíticas de evitar infecciones (Caffery, 1990; Kaufman y Alm, 2004).

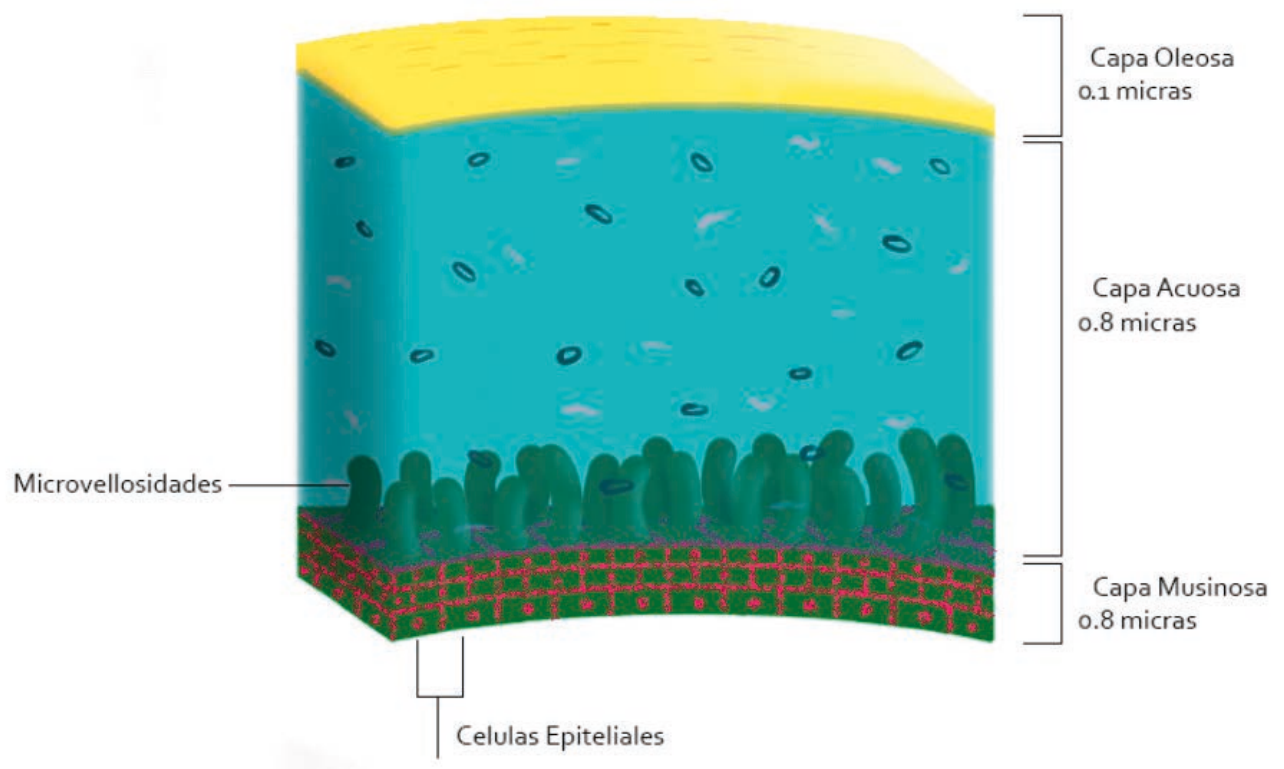

La inervación ${ }^{3}$ de la glándula lagrimal principal es regulada mayormente por el sistema nervioso involuntario, se conecta con la retina, la capa del ojo encargada de percibir la luz, y con el sistema límbico, el cual regula las emociones. Por este motivo podemos llorar en casos de deslumbramientos o por tristeza. Las concentraciones de electrolitos y proteínas de la subcapa acuosa variaran dependiendo del origen del estímulo (Kaufman y Alm, 2004).

Finalmente, la subcapa lipídica es la más externa, pues entra directamente en contacto con el aire. Proviene de las glándulas de Meibomio (ver figura 2) y se forma de la combinación de alcoholes con ácidos orgánicos (ésteres) y colesterol. Retrasa la evaporación de nuestras lágrimas, permitiendo que permanezcan por más tiempo sobre la superficie externa de nuestro ojo (Caffery, 1990; Kaufman y Alm, 2004).

\section{Una vez que las lágrimas han cumplido su función...}

En condiciones normales, se pierde entre 10\% y 20\% de la película lagrimal por evaporación. El parpadeo hace un efecto de sifón que bombea las lágrimas para su deshecho, iniciando con los puntos lagrimales en el borde interno de los párpados, continuando por los canales lagrimales y saco lagrimal hacia la nariz (Saraux, Lemasson, Offret, y Renard, 1985; ver figura 4).
${ }^{3}$ Conexión nerviosa encargada de activar su función. 
Figura 4. Aparato lagrimal. Fuente: elaboración propia.

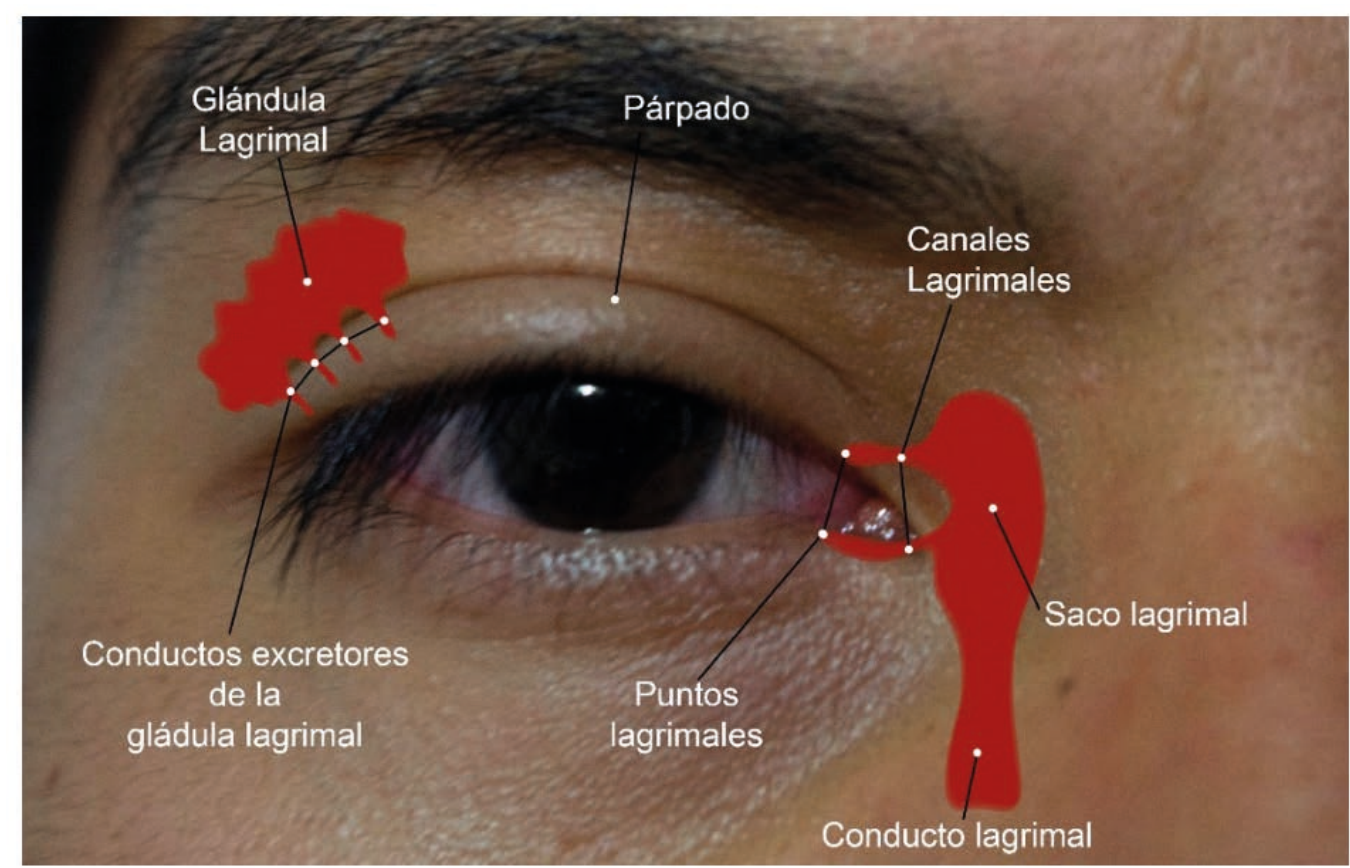

\section{Cuando las lágrimas tienen problemas se pueden presentar alteraciones}

El síndrome de ojo seco es la más frecuente, aparece por deficiencias en uno o en varios componentes. Entre sus síntomas, puede presentar sensación de tener arena o algo en el ojo, comezón, ardor, sensibilidad a la luz, pesadez en los párpados y a veces hasta dolor.

¿Has tratado de enfocar y no puedes? Si la película lagrimal se vuelve irregular, cuando la luz pase a través de ella también tendrá anormalidades (llamadas microaberraciones), lo que suele ocasionar que mientras fijamos la mirada en un objeto no se vea completamente definido (aun usando lentes). A veces, durante esos momentos empezamos a parpadear buscando mejorar el enfoque, porque al hacerlo volvemos a distribuir la lágrima de manera uniforme y a lubricar la superficie ocular, pero como ésta desaparece rápidamente resurgen las imágenes borrosas o distorsionadas que disminuyen la nitidez, por lo tanto continuamos parpadeando.

Otras causas del síndrome del ojo seco pueden ser mecánicas o autoinmunes:

- Mecánicas: Ios párpados laxos, el cierre incompleto del párpado o la disminución de la frecuencia del parpadeo propician un ojo seco pero funcional, ya que las capas de la lágrima se encuentran en una excelente condición de salud. 
- Autoinmunes (enfermedades donde nuestro propio sistema inmunológico ataca nuestros órganos sanos): síndrome Sjögren, ${ }_{1}^{4}$ queratoconjuntivitis sicca, ${ }^{5}$ desordenes de la glándula lagrimal, ${ }^{6}$ entre otros.

El síndrome de ojo seco, de igual modo, tiende a manifestarse por problemas en el resto del aparato lagrimal, en los puntos y conductos que llevan a su drenaje (Paul-Riorda y Emmet, 2011).

- Dacriocistitis: infección del saco lagrimal.

- Dacrioadenitis: inflamación de glándulas lagrimales. Puede volverse crónica, cuya causa más común es el síndrome de Sjögren, o aguda, debido a virus, bacterias u hongos.

- Epífora funcional u obstructiva: cuando el canal está obstruido por secreciones, lo que provoca lagrimeos excesivos.

\section{Otros padecimientos...}

- Alácrima: carencia congénita de lagrimeo.

- Lagrimación paradójica o lágrimas de cocodrilo: lagrimeo al comer.

- Lágrimas sanguinolentas o hemolacria: la presencia de sangre puede estar asociada con conjuntivitis, golpes o tumores.

\section{Evalúa si vives con un padecimiento lagrimal}

La siguiente información será de utilidad para descubrir si se vive con un padecimiento debido a problemas lagrimales.

Primero te sugerimos una autoevaluación respondiendo un cuestionario. Existen varios cuestionarios para determinar los síntomas de la resequedad ocular, uno de los más usados es el de McMonnies y Ho (1987). Este cuestionario lo puedes utilizar para autoevaluarte y saber si vives con algún problema en tu lágrima que deba ser atendido por un especialista. Consiste en 13 preguntas de opción múltiple, al final cada respuesta corresponde a un puntaje, cuya suma dirá si tienes un problema o estás en riesgo de tenerlo. Recomendamos tener a la mano un lugar para anotar las respuestas. Comencemos.

1. ¿Te han recetado gotas o algún otro tratamiento para ojo seco?
a) Sí
b) $\mathrm{No}$
c) No sabe

${ }^{4}$ El sistema inmune ataca las células productoras de lágrima.

${ }^{5}$ Resequedad crónica de la superficie ocular.

2. ¿Has experimentado alguno o algunos de los siguientes síntomas oculares? Puedes seleccionar más de una opción.
a) Sensibilidad
b) Rasguños 

c) Resequedad
d) Arenosos
e) Quemazón

3. ¿Qué tan frecuentemente has experimentado esos síntomas?
a) Nunca
b) Algunas veces
c) A menudo
d) Constantemente

4. ¿Tus ojos son sensibles al humo del cigarrillo, smog, calefacción o aire acondicionado?
a) Sí
b) No
c) Algunas veces

5. ¿Tus ojos quedan muy irritados o enrojecidos después de nadar?
a) No aplica
b) Sí
c) No
d) Algunas veces

6. ¿Están tus ojos secos o irritados después de tomar alcohol?
a) No aplica
b) Sí
c) No
d) Algunas veces

7. ¿Utilizas gotas oftálmicas o medicamentos tales como...? Puedes seleccionar más de una opción.
a) Antihistamínicos (gotas u orales)
b) Diuréticos (para hipertensión)
c) Píldoras para dormir
d) Anticonceptivos
e) Tranquilizantes

8. ¿Padeces artritis?
a) Sí
b) $\mathrm{No}$
c) No sabe 
9. ¿Experimentas resequedad en nariz, boca, garganta, pecho o vagina?
a) Nunca
b) Algunas veces
c) A menudo
d) Constantemente

10. ¿Padeces alguna anormalidad en la tiroides?
a) Sí
b) No
c) No sabe

11. ¿Duermes con los ojos entreabiertos?
a) Sí
b) No
c) Algunas veces

12. ¿Tus ojos se encuentran irritados después de dormir?
a) Sí
b) $\mathrm{No}$
c) Algunas veces

13. Selecciona el puntaje correspondiente con tu género y edad.

\begin{tabular}{|c|c|c|}
\hline Género & Edad (años) & Puntaje \\
\hline Hombre o mujer & $<25$ & 0 \\
\hline Hombre & $25-25$ & 1 \\
\hline Mujer & $25-45$ & 3 \\
\hline Hombre & $>45$ & 2 \\
\hline Mujer & $>45$ & 6 \\
\hline
\end{tabular}

Ahora que contestaste todas las preguntas, en la siguiente tabla puedes conocer el puntaje asignado a cada respuesta. Para las preguntas 2 y 7 puedes sumar más de una respuesta considerando los síntomas que presentes.

\begin{tabular}{|c|c|c|c|c|c|}
\hline Pregunta & a & b & c & d & e \\
\hline 1 & 2 & 0 & 1 & & \\
\hline 2 & 1 & 1 & 1 & 1 & 1 \\
\hline 3 & 0 & 1 & 2 & 3 & \\
\hline 4 & 2 & 0 & 1 & & \\
\hline 5 & 0 & 2 & 0 & 1 & \\
\hline 6 & 0 & 2 & 0 & 1 & \\
\hline 7 & 1 & 1 & 1 & 1 & 1 \\
\hline
\end{tabular}




\begin{tabular}{|c|c|c|c|c|c|}
\hline 8 & 2 & 0 & 1 & & \\
\hline 9 & 0 & 1 & 2 & 3 & \\
\hline 10 & 2 & 0 & 1 & & \\
\hline 11 & 1 & 0 & 1 & & \\
\hline 12 & 2 & 0 & 1 & & \\
\hline
\end{tabular}

\section{Interpretación de resultados}

Si al sumar el puntaje de todas las preguntas el resultado es mayor a 20, es muy probable que vivas con ojo seco y no lo hayas identificado. En este caso, debes acudir lo más pronto posible con un especialista. Pero, si tu puntaje está entre 10 y 20, tus ojos están en riesgo, así que se recomienda tener una revisión más detallada para conocer tu condición de salud lagrimal. Para todos aquellos que tienen un resultado menor a 10, felicidades gozan de una calidad lagrimal saludable.

\section{Métodos de diagnóstico}

Los especialistas de la visión realizan diferentes métodos diagnósticos que van desde cuestionarios sobre los síntomas, los más conocidos son el de McMonnies y el osDi (Ocular Surface Disease Index), hasta pruebas especializadas de laboratorio. Los exámenes que generalmente se usan son: el test de Schirmer, el TBuT por sus siglas en inglés Tear Break up Time (tiempo de ruptura lagrimal, ver figura 5), y otros como hilo fenol, tinción con verde de lisamina o rosa de bengala. Estas muestras evalúan el volumen de producción lagrimal, el tiempo que mantiene su uniformidad sobre la superficie ocular y si existe algún tipo de daño en estructuras anteriores del ojo, como la córnea y conjuntiva, por resequedad. Algunos otros métodos menos invasivos incluyen grabar un video que determine la cantidad de lágrima que hay entre el párpado inferior y la superficie ocular (menisco lagrimal, ver figura 6).

Figura 5. Muestra del tBut. A la izquierda se observa la tinción distribuida uniformemente en el inicio de la prueba; a la derecha aparecen las zonas obscuras señaladas con flechas rojas, secciones donde ya se evaporó la lágrima. Fuente: elaboración propia.

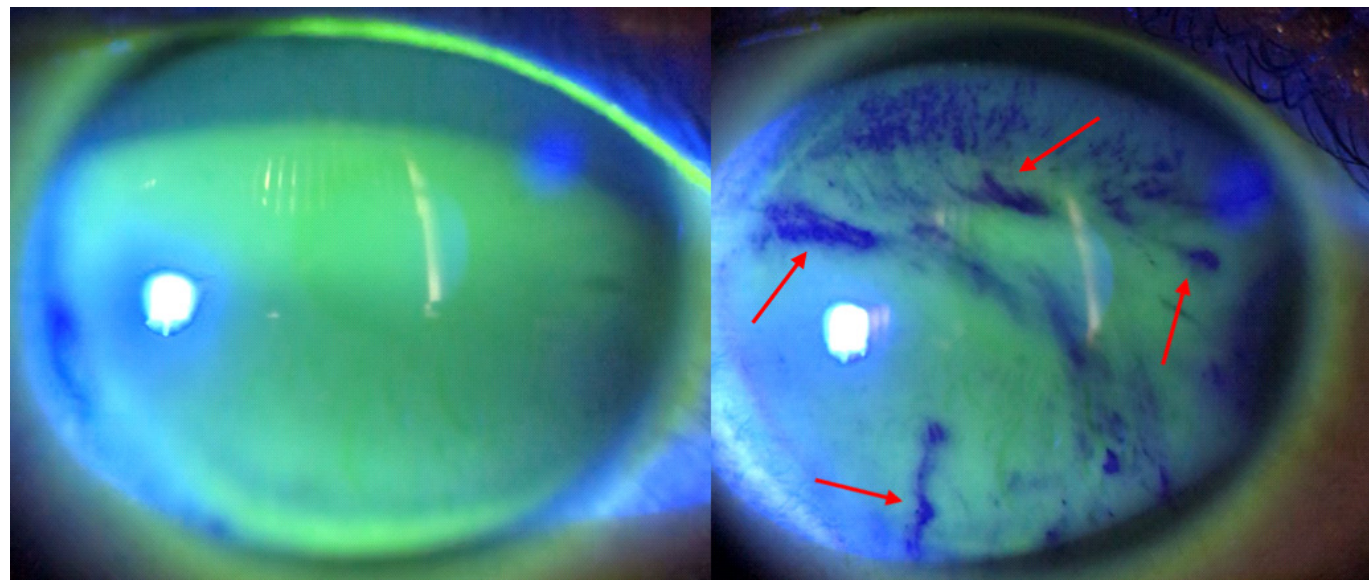

Otras técnicas no invasivas estiman, a nivel laboratorio, la concentración de las distintas sustancias que componen la lágrima (osmolaridad) y también se ha 
Figura 6. Menisco lagrimal. En un ojo sano, la altura del menisco debe ser de al menos 100 micras $(0.1 \mathrm{~mm})$. Fuente: elaboración propia. popularizado el uso de un equipo llamado tearscope, diseñado por Guillon en 1986, que permite dar un diagnóstico de ojo seco en cuestión de segundos (The vision Care Institute, s.f.).

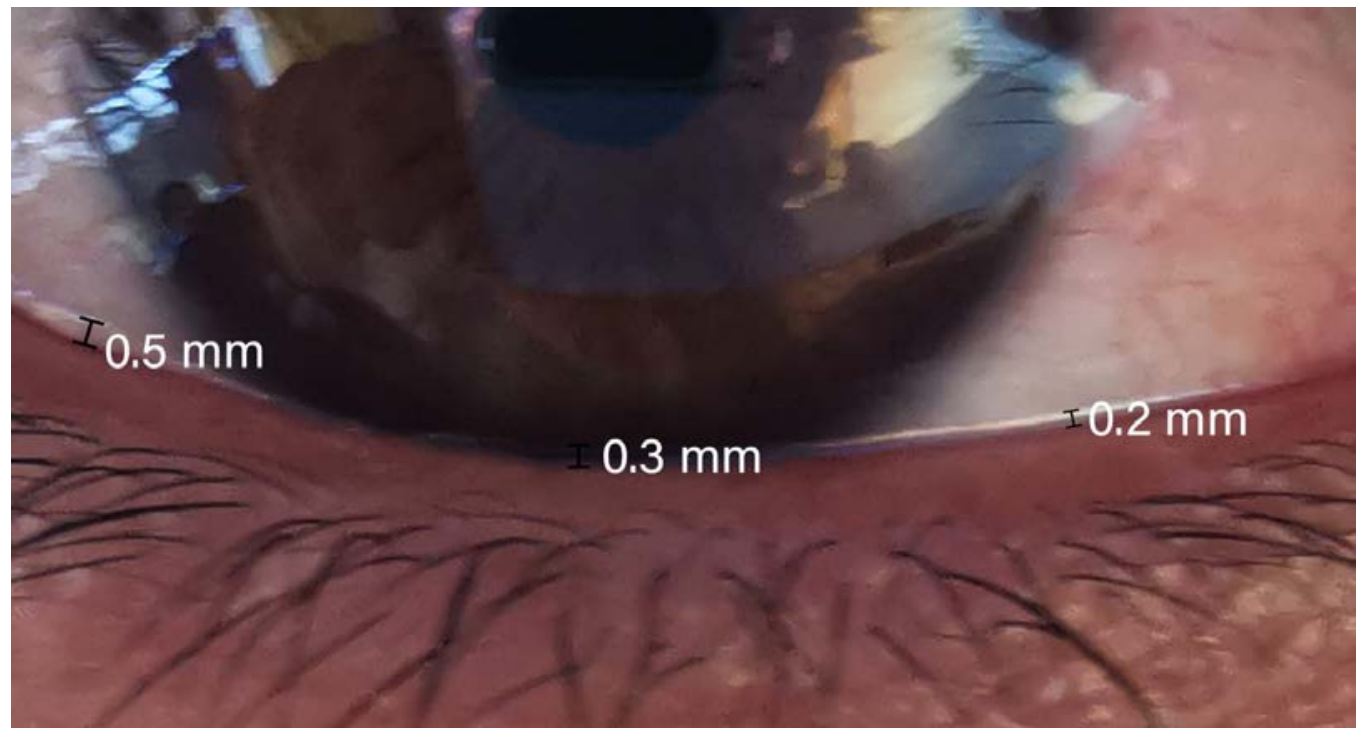

\section{Novedades en las investigaciones sobre la lágrima}

Se estudia la posibilidad de medir los componentes de la lágrima para el seguimiento de diferentes enfermedades. Se ha desarrollado el prototipo de unos lentes con un biosensor para monitorear la glucosa en pacientes diabéticos, sin necesidad de pincharse el dedo. Así como de lentes de contacto que pueden medir el nivel de glucosa a través de la glucosa en las lágrimas (Anteojos que monitorean la diabetes, 2020; UnAm Global, 2018).

\section{Datos importantes}

Entre los factores que favorecen la aparición de deficiencias en la película lagrimal se encuentran el uso constante de dispositivos electrónicos y de aire acondicionado (el parpadeo disminuye, entonces, el ojo se reseca), una dieta deficiente en omega 3 y vitamina A, así como habitar en ciudades con altos índices de contaminación.

\section{Conclusiones}

Deficiencias en la producción o en las características de cualquiera de las capas de la película lagrimal pueden dar origen a padecimientos en los ojos que afecten nuestro rendimiento visual. 
Los cuestionarios son útiles para distinguir algunos de los síntomas asociados con alteraciones de la película lagrimal; sin embargo, sólo un especialista de la visión podrá determinar el diagnóstico certero y tratamiento en cada caso. Por lo cual, si presentaste un puntaje de riesgo de ojo seco, será prudente acudas a una revisión detallada a fin de que recibas el tratamiento adecuado.

Los tratamientos para las deficiencias lagrimales son variados; algunos consisten en modificaciones en el medio ambiente y en la dieta, otros en el uso de geles, lágrimas artificiales, antiinflamatorios, antibióticos, tapones lagrimales, gafas de cámaras de humedad, lentes de contacto o procedimientos quirúrgicos. Pero cada una de estas opciones dependerá del origen de la afección.

\section{Referencias}

- Anteojos que monitorean la diabetes. (2020, 5 de febrero). Grupo Franja. https:// grupofranja.com/anteojos-que-monitorean-la-diabetes/

* Caffery, B. E. (1990, 2 de agosto). Influence of diet on tear function. Optom Vis Sci, 68(1), 58-712.

* Gayton, J. L. (2009, 7 de julio). Etiology, prevalence, and treatment of dry eye disease. Clinical Ophthalmology, 3, 405-412. Dol: https://www.doi.org/10.2147/ opth.s5555

* Kaufman, P. L., y Alm, A. (2004). Adler fisiología del ojo. Aplicación clínica. Elsevier.

* McMonnies, C. W., y Ho, A. (1987). Patient history in screening for dry eye conditions. J Am Optom Assoc, 58(4), 296-301.

* Paul-Riorda, E., y Emmet, T. C. (2011). Vaughan y Asbury. Oftalmología general. Mc Graw Hill.

* Saraux, H., Lemasson, C., Offret, H., y Renard, G. (1985). Anatomía e histología del ojo. Masson.

* The Vision Care Institute. (s.f.). Prácticas Esenciales con Lentes de Contacto. Estudio de la película lagrimal. Johnson \& Johnson Medical. https://www.jnjvisioncare. es/sites/default/files/public/es/documents/educational_moments/1/examen_ pelicula_lagrimal.pdf

* unam Global. (2018, 23 de marzo). Así son los nuevos lentes de contacto para diabéticos. Excélsior. https://www.excelsior.com.mx/nacional/2018/03/23/1228186

\section{Cómo CITAR ESTe ARTículo}

* Sánchez Sánchez, Anabel Socorro y Rodriguez Mercado, Alejandro. (2020, septiembre-octubre). Las lágrimas y sus padecimientos. Revista Digital Universitaria (RDU), 21(5). Dol: http://doi.org/10.22201/cuaieed.16076079e.2020.21.5.6 